\title{
IMPLEMENTATION OF SCL PROTOCOL TO ENSURE THE CONSTRUCTION SUSTAINABILITY DURING THE EXECUTION STAGE
}

\author{
MAYOORASAKITHIAN T. ${ }^{1}$, ABEYNAYAKE M.D.T.E. ${ }^{2} \&$ LIYANAGE K.L.A.K.T. ${ }^{3}$ \\ 1,2,3 University of Moratuwa, Moratuwa, Sri Lanka. \\ 1sakithianqs@gmail.com, 2abey92@hotmail.com,3kushiliyanage23@gmail.com
}

\begin{abstract}
In the Sri Lankan construction industry, the wrong industry practices and undefined areas about delay and disruption in the contract causes the disputes. Significantly, the disputes cause controversial issues in the quality of the working relationship. Accordingly, the negative impact on the working relationship affects construction sustainability during the execution stage. Here, the implementation of the SCL protocol for the claim management would overcome the above mentioned problem. The aim of the research was designed with modifying the SCL protocol to best suit the Sri Lankan claims management and hence to improve quality of working relationship. Thus, the expert interviews from five experts set out the feasibility and practicability of the SCL protocol in Sri Lanka. Here, the experts having more than 10 years of experience in claims management were selected through snowball sampling and the collected data was analysed through code based content analysis using NVivo. Finally, the suggestions for the modification of the core principles in SCL protocol to match with the current Sri Lankan practices and the practical difficulties to implement the SCL protocol were determined. Ultimately, the modification and implementation of the SCL protocol together would enhance the construction sustainability during the execution stage.
\end{abstract}

Keywords: Disputes, Delay and Disruption, Sustainability, SCL protocol.

\section{Introduction}

Sustainable development has significant impacts on the evolution of the construction industry (Ahmad, Mazhar, Laedre, Bruland, \& Torp, 2019). In fact, it is the responsibility of the construction industry to attain sustainability throughout the construction process (Vatalis, Manoliadis, \& Charalampides, 2011). Here, sustainable development concern about the environmental, social and economic aspects of the construction (Tan, Shen, \& Yao, 2011). Narrowing to economic sustainability, the construction industry faces challenges during the different stages of construction process (Vatalis et al., 2011).

Currently, the construction professionals are looking forward to implementing sustainable policies during the execution stage (Tan et al., 2011). Accordingly, the sustainablity in the execution stage can be achieved through effective procurement and good working relationships (Jelodar, Yiu, \& Wilkinson, 2013). Significantly, the working relatioship in constrction project is formed after signing the contract (Jelodar, Yiu, \& Wilkinson, 2016). Accordingly, good quality relationship would minimise the excess cost associated with the construction project (Jelodar et al., 2013). Moreover, the above mentioned sustainable relationship ensure the collaboration, trust, and commitment among the professionals and enhance the overall value of the project in terms of quality, time and cost (Jelodar et al., 2016).

Construction projects often suffer from controversial issues during the execution stage due to unforeseeable situation (Pinamang, Gyamfi, Danso, \& Kwame, 2018). Consequently, the above situation leads to delay and disruption in the construction projects (Keane \& Caletka, 2015). Here, both delay and disruption have considerable effects on the time and cost of construction projects (Aibinu, 2009). Accordingly, the reason for the issues could be due to the vague areas in delay and disruption that are not clearly expressed in the construction contract (Jayalath, 2012). Therefore, it is vital to have a universal approach or acceptable guideline to minimize or mitigate the disputes arising out of delay and disruption in the construction industry (Taylor, 2010).

Accordingly, guidelines such as "SCL (Society of Construction Law) Protocol" and "Forensic Schedule Analysis" are developed to overcome the vague areas in the expressed conditions of the contract to deal delay and disruption claim management (Keane \& Caletka, 2015). Here, compared to forensic 
schedule analysis delay and disruption protocol is more comprehensive (Association for the Advancement of Cost Engineering International (AACEI), 2011). In addition, delay and disruption protocol is widely used in many countries (Braimah, 2013). Anyhow, different countries may have different national culture and hence, investigation, the magnitude of delay, causes, effects, and remedies may vary (Arditi, Nayak, \& Damci, 2016). Therefore, it is required to prove the adaptability of the protocol in Sri Lanka and hence, (Pathirana \& Seneviratne, 2015) have proved the feasibility of adopting delay and disruption protocol in the Sri Lankan claim management.

Even though the SCL protocol is feasible in Sri Lanka, only 33\% of total respondent have practicing SCL protocol (Pathirana \& Seneviratne, 2015). Hence, there is a necessity to modify the SCL protocol to best suit the Sri Lankan practices and to improve the practicality. Accordingly, the aim of the research was developed to modify the SCL protocol to best suit the Sri Lankan claims management and hence to ensure the construction sustainability during the execution stage. Eventually, the objectives were to determine the disputes arising out of delay and disruption claims, core principles in SCL protocol and adaptability of SCL protocol to Sri Lankan construction industry.

\section{Issues due to delay and disruption in Sri Lankan construction industry}

In Sri Lankan context, unclear areas in delay and disruption are the reason for the difficulty in establishing the fair and expeditious settlement of claims (Pathirana \& Seneviratne, 2015). Here, the unclear areas in delay and disruption are referred to as improper updating programme, concurrent delays, float and selection of suitable Delay Analysis Technique (DAT) (Pathirana \& Seneviratne, 2015). Further, the confidentiality on the delay analysis process is poor among the parties in Sri Lanka (National Construction Association of Sri Lanka, 2014). Moreover, the failure of notifying the claim at the right time is also a reason for the rejection of delay claims (Ramachandra, Rotimi, \& Gunaratne, 2014). Ultimately, 78-90\% of construction projects in Sri Lanka are suffered from time overrun, among them, $50-70 \%$ of the projects have submitted delay claims, and out of the submitted claim only 25-40\% of claims were succeeded (Ramachandra et al., 2014). Therefore, the delay claims in the Sri Lankan construction industry sentence to dispute among the parties to the contract (Perera, Wijewickrama, Goonawardana, \& Jayalath, 2019).The disruption claims are poorly practice in Sri Lanka due to less guidance and case law on disruption analysis, less awareness of situations, lack of records availability, level of awareness about proving contractual entitlement for recovery of the disruption event, unavailability of the proper baseline programme, lack of awareness of the disruption quantifying methodologies, concurrent disruption, and lack of skilled site staff and poor communication and coordination (Jayasena \& Alwis, 2011). Ultimately, issues regarding delay and disruption should be mitigated in order to prevent the dispute situation (Pathirana \& Seneviratne, 2015).

\subsection{MITIGATING ISSUES IN DELAY AND DISRUPTION CLAIM MANAGEMENT}

Here, issues in delay analysis can be mitigated in a fair and amicable manner through awareness and incorporation (Braimah, 2013). Consequently, above-mentioned issues in delay and disruptions can be mitigated through studying the mechanism and proper ways (Pathirana \& Seneviratne, 2015). Accordingly, proper guideline for delay and disruption is required for the parties to the contract (Tan, 2012). Therefore, introducing a guideline to mitigate delay and disruption claim would be a better solution before it becomes complex (Braimah, 2008). Accordingly, most notable guidelines are SCL protocol and Forensic Schedule Analysis (Braimah, 2013). When narrowing down to Sri Lankan construction industry, a current research has identified that out of the above-mentioned guidelines only $40 \%$ of total respondents were aware of the SCL protocol and $20 \%$ of total respondent were aware of the RP-FSA guideline (Pathirana \& Seneviratne, 2015).

\subsection{SCL’S DELAY AND DISRUPTION PROTOCOL}

SCL has published delay and disruption protocol in October 2002 (Tan, 2012). Thereafter, the 2nd edition was published by SCL in February 2017 (Society of Construction Law (SCL), 2017). Accordingly, the main purpose of the protocol was to determine the EOT and compensation for delay 
and disruption claim (Shahsavand, Marefat, \& Parchamijalal, 2018). Moreover, it recommends the management procedure for managing, predicting and determine the impact during execution of the project and focus to avoid disputes among parties (Keane \& Caletka, 2015). Hence, the protocol provides information to prevent and resolve disputed that arise in the construction industry (SCL, 2017). Ultimately, SCL protocol provide guidance under 22 core principles about vague areas in delay and disruption claim management (Klee, 2018).

\subsection{GUIDANCE ON CORE PRINCIPLES IN DELAY AND DISRUPTION PROTOCOL}

According to Aibinu (2009), SCL protocol provide rules for assesing and quantifying claims regarding delay and disruption during pre-contract stage and post contract stage. Here, this protocol has clauses for reducing dispute costs, improving efficiency, and ensuring transparency and professionalism are considered to be benefits (Ward, 2011). Among the 22 core principles in the SCL protocol, the significant principles regarding claims management were elaborated below.

\subsubsection{Programme and records}

Disputes can be minimised to an extent using proper record keeping (SCL, 2017). SCL protocol suggests having an agreement for the type of records to be maintained (Keane \& Caletka, 2015). Accordingly, records must be recorded contemporaneously and consistent with work progress (SCL, 2017). In order to establish the quality in record-keeping, contractor requires an investment of cost, time, and commitment of staff (SCL, 2017). Therefore, the contractor's obligation of record-keeping should be included in the tender and allow to price accurate for the requirement of records (SCL, 2017).

\subsubsection{Contemporaneous analysis}

According to SCL (2017), the time impact of ERE (Employer Responsible Event) should be dealt within a short time. Therefore, the EOT (Extension of Time) application should be submitted at the time the event occurs (Keane \& Caletka, 2015). Further, the CA (Contract Administrator) should asses the EOT application within a reasonable time after the submission by the contractor (SCL, 2017). Ultimately, the protocol suggests that wait and see approach should be avoided because assessing the impact later would not be accurate (Keane \& Caletka, 2015).

\subsubsection{Float as it relates to time}

Float is the criticality of an activity that can be delayed without affecting the overall completion date (Nagata, Manginelli, Lowe, \& Trauner, 2018). However, exhausting the float would have some impact on the contract completion date (SCL, 2017). According to SCL, 2017, EOT should not be granted until the total float reduced to zero. As a result, there is a different argument on the ownership of float such as contractor owns the float, the employer owns the float and for the benefit of the project (Keane \& Caletka, 2015). According to the contractor, the float was to give some relaxation and flexibility to carry out the work and it has been proposed during the planning (SCL, 2017). Conversely, the employer may argue that the delay event should affect the contract completion date unless the contractor has no entitlement to EOT (SCL, 2017). Therefore, the contract should address the ownership of float and the practical effects of permutation (SCL, 2017).

\subsubsection{Concurrent delay}

Concurrent delay is a vague area in claims management where most of the dispute arises (Baduge \& Jayasena, 2012). According to Kikwasi (2013), both contractor and client are responsible for the concurrent delay. However, concurrency is used as a shield by both parties in defending delay claims (Baduge \& Jayasena, 2012). As a result, the client will argue the contractor is responsible for the concurrent delay to avoid additional compensation, whereas, the contractors argue the client is responsible to avoid a claim for liquidated damages (Trauner, Manginelli, Lowe, Nagata, \& Furniss, 2009). Here, the concurrent delay may have the occurrence on a similar critical path or may have on 
the separate path (Nagata et al., 2018). Ultimately, the contractor shall be entitled to EOT during the concurrent delay for EREs (Keane \& Caletka, 2015).The contractor has the entitlement to claim cost for events directly result from compensable delay (Keane \& Caletka, 2015). However, the contractor is required to prove the additional cost has incurred from employer delay to completion and not from contractor delay to completion (SCL, 2017). Moreover, in a situation that those additional costs are not able to separate from non-compensable causes then the contractor is not entitled to an additional cost (Keane \& Caletka, 2015).

\subsubsection{Analysis time-distant from the delay event}

Delay analysis is the calculation to determine the entitlement for compensation to either party in terms of the time and/or cost (Braimah, 2013). Thus, DAT must integrate the available information such as the dynamic nature of a construction schedule and critical path (Ennis, 2011). Currently, Impacted As-Planned, Time Impact Analysis, Collapsed As-Built, As-Planned vs. As-Built, and Global Impact Technique are used as DATs in Sri Lanka (Perera \& Sudeha, 2013).

Impacted As-Planned is used to measure the impact of delay on the as-planned Critical path Method (CPM) schedule (Braimah, 2013). In order to measure the impact, delay analyst has to insert the delay events into the as-planned schedule (Nagata et al., 2018). Here, the difference between the completion dates in the as-planned CPM schedule before and after the impact will provide the total amount of delay (Baker, 2014). Time Impact Analysis is used to determine the effect of the delays on the updated as-planned schedule (Braimah, 2008). Rather than using the original as-planned baseline, this method uses multiple baselines for the analysis (Keane \& Caletka, 2015), and each delay events are inserted one by one on the updated as-planned schedule (Braimah, 2008). Thereafter, the new completion date is identified as per the updated schedule during the delay period (Braimah, 2013). Here, the amount of delay caused is the difference between the new completion date and the date prior to the impact (Nagata et al., 2018).

Collapsed As-Built Analysis is based on the contractor's actual sequences and durations (Keane \& Caletka, 2015). Accordingly, the analyst prepares a detailed as-built schedule based on the contemporaneous records (Nagata et al., 2018). After that, the EREs are extracted from the as-built program and hence, the delay impact on the project for the contractor is determined (AACEI, 2011). Moreover, the logical relation between the scheduled activities is also inserted in this method (Nagata et al., 2018). According to As-planned v As-build method, it first identifies the critical path in the asplanned programme and then, delays events are inserted into the as-built programme (Baker, 2014). Thereafter, the critical path in the as-built schedule is identified (Ekanayake \& Perera, 2016). Here, the amount of delay is the difference between the completion dates of the as-planned schedule and asbuilt schedule (Braimah, 2013).

\subsubsection{Mitigation of delay and mitigation of loss}

The contractor has a general duty to mitigate the actual effects or potential losses due to ERE (Keane \& Caletka, 2015). Accordingly, the contractor has to determine the appropriate mitigation measures to limit the impact of the delay event (SCL, 2017). However, the contractor is not supposed to assign extra resources or to work outside the planned working hours to mitigate the effects (Gibson, 2015). Conversely, if the employer insists the contractor to take measure then the employer should pay the incurred cost (SCL, 2017). Moreover, (SCL, 2017) highlighted that the contractor must take reasonable steps to minimise its loss and not to take unreasonable steps to increase its loss.

\subsubsection{Acceleration}

Contractor's progress may fall behind the planned programme due to many reasons (Keane \& Caletka, 2015). In order, to complete the work in less time compared to the earlier plan, the contractor may accelerate the progress (Gibson, 2015). Here, acceleration directly links to the progress of a construction project to complete the original scope of work (Nagata et al., 2018). Accordingly, the cost of acceleration is the liability of the party responsible for the delay and/or party instructing to 
accelerate (Gibson, 2015). Moreover, the payment for acceleration should be agreed between the parties prior to commencing the acceleration (Keane \& Caletka, 2015). While the parties agreed for acceleration measures, the contractor is not an entitlement for prolongation (SCL, 2017).

\subsubsection{Global claims}

According to (SCL, 2017), it discourages the contractor's approach towards making the global claim without attempting to determine the cause and effect (SCL, 2017). Further, the protocol suggests that global claims can be avoided if the contractor has maintained accurate and complete records (SCL, 2017). Initially, quantify individually the claim for which the causal link can be established between the ERE and the resultant costs and/or loss claimed and then reminding claim for compensation can be claimed as a composite whole and here, the contractor need to establish the event for which this claim is made

\subsubsection{Disruption claims}

Disruption measuring techniques have been developed to analyze efficiency or to calculate the loss of productivity in construction projects (Keane \& Caletka, 2015). Here, these techniques are used to prove the productivity loss or inefficiencies that were caused due to disruption event (Braimah, 2008). According to the SCL (2017), disruption measuring techniques can be categorized as productivitybased methods and cost-based methods here, productivity-based methods include project-specific studies, project-comparison studies, and industry studies. Project-specific studies are based on the people and records that are directly involved at the time of the disputed work (Nelson, 2011).

Measured mile analysis is used to compare the actual cost between the operations of the work in undisrupted periods with the same work affected by the alleged disruption (Ennis, 2011). At first, the labour productivity ratios during the non-impacted performance period to be calculated (Ennis, 2011). Earned value analysis is used to compare the number of man-hours required to complete the work as stated in the tender with the actual number of man-hours required to complete the particular work (SCL, 2017). Here, this method uses the three-dimension to measure the project performance such as budgeted cost of work schedule, budgeted cost of work performed and the actual cost of work performed (Braimah, 2008).

Programme analysis is based on the specialist software that tracks and allocate resources such as labour, cost, plant, and quantities over the project life (SCL, 2017). In detail, it is used to calculate both the periodic completion percentage and earned value for disrupted activities based on the provided information (SCL, 2017). Work or trade sampling method is used to determine productivity based on contemporaneous records that are obtained from direct observation of work (SCL, 2017). Accordingly, this method uses work sampling and craftsmen questionnaire sampling to estimate the loss of productivity (Nelson, 2011). System dynamic modelling is a comprehensive dynamic computer model that maps all relationships and feedback loops of the disrupted project (Nelson, 2011). Here, the cause and effect structure is developed to trace how the disruption occurred (Braimah, 2008).

Project-comparison studies can be used when the available records are insufficient to carry out the project-specific study (SCL, 2017). Undoubtedly, this method is a benchmark in deriving productivity factor to compare with the productivity achieved in the disrupted work (Ennis, 2011). Here, the productivity factor is determined from similar or equivalent projects where the disruption events are not occurred (SCL, 2017). Industry studies is a solution to determine loss of productivity where the contemporaneous records are insufficient to carry out the project-specific study or project-comparison studies (SCL, 2017). Here, the productivity rates that are recognized and accepted by the construction industry are used to compare with actual productivity observed during the alleged disrupted period (Ennis, 2011). Cost-based methods can be used to measure the loss of productivity only if the available contemporaneous records are insufficient to carry out the productivity-based approach (Nelson, 2011). Accordingly, this method measures the productivity as the difference between the actual cost and the contractual cost, here, the causal link between the reason for the loss of productivity and quantity of corresponding productivity loss is not considered (Braimah, 2008; SCL, 2017). 


\subsection{FEASIBILITY OF SCL PROTOCOL IN SRI LANKA}

In addition, the implementation of SCL protocol would be beneficial for the proper delay and disruption claim management in Sri Lanka (Pathirana \& Seneviratne, 2015). Guidance in SCL protocol are not contradict with FIDIC (Federation Internationale Des Ingenieurs-Conseils) and SBD (Standard Bidding Document) conditions which are commonly used as conditions of contract in Sri Lanka (Pathirana \& Seneviratne, 2015). Therefore, guidance in this protocol can be used in harmony with the contract provision for the delay and disruption claim management in Sri Lanka (Jayasena \& Alwis, 2011). Ultimately, majority of Sri Lankan professional accepted that SCL protocol would provide effective guidance (Pathirana \& Seneviratne, 2015). However, most of the claim practitioners in Sri Lanka are not practicing SCL protocol (Pathirana \& Seneviratne, 2015), due to unfamiliarity, lack of qualified professional, unawareness, government requirements, bureaucratic procedures, thinking attitudes of professionals, and employers are not interested to use SCL protocol (Pathirana \& Seneviratne, 2015).

\section{Research methodology}

A comprehensive literature review was carried to gather knowledge about sustainable development during execution stage, disputes arising out of claims management, core principles in SCL protocol and the feasibility of SCL protocol in Sri Lanka. Significantly, the qualitative approach was implemented to have vast insight and perceptions of people's understanding about the research problem. Accordingly, the qualitative approach was designed with the expert interviews to explore the practicality of the SCL protocol for the Sri Lanka construction industry. Furthermore, the interviews were designed with the semi-structured interviews to give freedom of opinion of the experts. Particularly, the snowball sampling was used due to the difficulties in finding the claim specialist who have more than 10 years of experience in the claim management and hence, five experts were selected. Subsequently, the analysis was carried out with the code based content analysis using NVivo software.

\section{Findings through expert interviews}

\subsection{CONTRADICTIONS IN SCL PRINCIPLES TO IMPLEMENT IN SRI LANKA}

Expert interviewees highlighted the contradictory principles in the SCL protocol to use as guidance in Sri Lankan construction industry. Further, the interviewees have suggested the principles that suits Sri Lanka compared to core principles in the protocol. According to the above suggestions, the details were tabulated in the following Table 1.

Table 1: Contradiction in the SCL protocol to implement in Sri Lanka

\begin{tabular}{|l|l|}
\hline \multicolumn{1}{|c|}{ Core principle in SCL protocol } & \multicolumn{1}{c|}{ Suggested principle to Sri Lanka } \\
\hline $\begin{array}{l}\text { Float in the programme is for the benefit } \\
\text { of the project and parties shall not take } \\
\text { advantage of float }\end{array}$ & $\begin{array}{l}\text { Contractor shall be allowed to reschedule the programme and shall } \\
\text { reschedule without float }\end{array}$ \\
\cline { 2 - 2 } & $\begin{array}{l}\text { CA has to consider the contractor's resource allocation, shall not } \\
\text { expect same resource allocation throughout the project }\end{array}$ \\
\hline $\begin{array}{l}\text { Contractor can claim for additional cost } \\
\text { caused by the employer delay can initiate } \\
\text { to determine EOT in a situation the } \\
\text { contractor }\end{array}$ & $\begin{array}{l}\text { In business perspective, contractor to be paid for resources } \\
\text { allocated to execute employer's work while the employer also have } \\
\text { delayed }\end{array}$ \\
\hline CA on his own fails to do so & $\begin{array}{l}\text { FIDIC and SBD recommend, contractor have to initiate the claim. } \\
\text { Here, with submission of notice CA cannot evaluate the claim }\end{array}$ \\
\hline $\begin{array}{l}\text { Contractor has to submit the programme } \\
\text { and CA has to approve the programme, } \\
\text { both party liable for programme }\end{array}$ & $\begin{array}{l}\text { FIDIC and SBD recommend, CA shall give comments and not liable } \\
\text { for the contractor's programme }\end{array}$ \\
\hline
\end{tabular}

\subsection{CURRENT SRI LANKAN PRACTICES IN CLAIMS MANAGEMENT}

Moreover, the interviewees have emphasized the current Sri Lankan practices in claim management that contradict with core principles in the protocol. Further, the interviewees have mentioned about 
the consequences arising out of the current Sri Lankan practices. Ultimately, the following table 2 depict the Sri Lankan practices and consequences arising out of that.

Table 2: Current Sri Lankan practices in claims management

\begin{tabular}{|l|l|}
\hline Current Sri Lankan Practice & \multicolumn{1}{c|}{ Consequences } \\
\hline $\begin{array}{l}\text { Contractor rarely submit the claim } \\
\text { notice to the employer within } \\
\text { reasonable time }\end{array}$ & $\begin{array}{l}\text { Last minute submission of notice would cause financial barriers for the } \\
\text { employer to settle all claims, because employer may have limited budget } \\
\text { allocation for the project. }\end{array}$ \\
\hline $\begin{array}{l}\text { Contractor claim the } \\
\text { compensation for delay at the end } \\
\text { of the project based on the actual } \\
\text { cost incurred for the extended } \\
\text { contract period. }\end{array}$ & $\begin{array}{l}\text { Difficulties for the contractor to collect the records to substantiate the } \\
\text { claim, because the professionals who are responsible for record-keeping } \\
\text { may not available at the end of project. }\end{array}$ \\
\hline $\begin{array}{l}\text { Contractor often submit global } \\
\text { claim and fail to separate the } \\
\text { cause and effects of each claims }\end{array}$ & Either party would not be satisfied on the compensation for global claim. \\
\hline $\begin{array}{l}\text { Contractor rarely update and } \\
\text { submit the programme monthly }\end{array}$ & $\begin{array}{l}\text { Contractor not follows the construction sequence so difficult to prove the } \\
\text { progress }\end{array}$ \\
\hline
\end{tabular}

\subsection{PRACTICAL DIFFICULTIES IN SRI LANKAN CLAIMS MANAGEMENT}

In addition, interviewees have also identified the practical difficulties in claim management. Accordingly, the following table 4.3 was designed to elaborate the practical difficulties along with the reasons for the difficulties in claim management in Sri Lankan construction industry. Hence, these practical difficulties are the root cause for the above mentioned Sri Lankan practices in claim management explained in Table 2

Table 3: Practical difficulties in Sri Lankan claims management

\begin{tabular}{|l|l|}
\hline \multicolumn{1}{|c|}{ Practical difficulties } & \multicolumn{1}{c|}{ Reason for difficulties } \\
\hline $\begin{array}{l}\text { Limited quantity surveyors are employed in the } \\
\text { site to carry out claim process and day to day site } \\
\text { works }\end{array}$ & $\begin{array}{l}\text { To win the competitive tender, contractor reduce } \\
\text { overhead as a result limited number of staff employed }\end{array}$ \\
\hline $\begin{array}{l}\text { Contractor could not able maintain the planned } \\
\text { labour resources during the execution of work }\end{array}$ & $\begin{array}{l}\text { Contractor has no fixed labour resources throughout the } \\
\text { project, obviously labour resource fluctuate }\end{array}$ \\
\hline $\begin{array}{l}\text { Contractor could not able to maintain the as- } \\
\text { built programme by updating the programme } \\
\text { daily based on actual work done }\end{array}$ & $\begin{array}{l}\text { To win the competitive tender, contractor reduce } \\
\text { overhead as a result limited the number of staff employed }\end{array}$ \\
\hline $\begin{array}{l}\text { Contractor could not able to manage activities in } \\
\text { programme and update the programme in every } \\
\text { monthly intervals }\end{array}$ & $\begin{array}{l}\text { Activity duration in the programme may have more than } \\
\text { 30 days due to contractor's method of construction }\end{array}$ \\
\hline
\end{tabular}

Significantly, most of the expert interviewees expressed the feasibility and practicality of the SCL protocol to Sri Lankan construction industry. Accordingly, the proper implementation of the protocol would help to enhance the Sri Lankan practices in claims management. Ultimately, it would minimize the disputes arising out of current Sri Lankan practice.

\section{Conclusions}

Sustainable development during the execution stage has considerable impact on the economic sustainability. Significantly, the sustainability during the execution stage can be achieved through good quality working relationship. On the other hand, the disputes arising in the construction industry have negative influence in the quality of working relationship. Here, the undefined areas of delay and disruption claims management in the condition of contract were the main cause of disputes. However, there are universal accepted guidelines to address the above mentioned undefined areas. Accordingly, the SCL protocol and Forensic Schedule Analysis were identified as notable guidelines in the construction industry. Subsequently, the SCL protocol is deemed as the best guideline for Sri Lankan 
claim management. Further, the analysis of expert interviews has suggested the modification to the core principles to best suit the Sri Lankan construction industry. Even though the implementation has practical difficulties, the effective modification and implementation of SCL protocol together would enhance the collaborative working relationship among different professionals. Obviously, it would minimise the disputes in the construction industry. Ultimately, it prevent the project being overrun in terms of cost and time and also ensure the effective and efficient construction during the execution stage.

\section{References}

Ahmad, S. S., Mazhar, M. U., Laedre, O., Bruland, A., \& Torp, O. (2019). Improvement measures to achieve sustainable construction labour. International Journal Of Construction Management, 18.

Aibinu, A. A. (2009). Avoiding and Mitigating Delay and Disruption Claims Conflict: Role of Precontract Negotiation. Journal of Legal Affairs and Dispute Resolution in Engineering and Construction, 1(1), 47-58.

Arditi, D., Nayak, S., \& Damci, A. (2016). Effect of organizational culture on delay in construction. International Journal of Project Management, 35(2), 136-147.

Baduge, S., \& Jayasena, H. S. (2012). Application of Concurrent Delay claims. In Proceeding of World Construction Conference 2012 - Global Challenges in Construction Industry, (pp. 69-78).

Baker, K. R. (2014). Presenting delay claims: Where is the logic? Retrieved from https://twiter.com/LormanEducation

Braimah, N. (2008). An Investigation Into The Use Of Construction Delay And Disruption Analysis Methodologies. Wolverhampton: University of Wolverhampton.

Braimah, N. (2013). Construction Delay Analysis Techniques-A Review of Application Issues and Improvement Needs. Buildings, 3, 506-531.

Dolage, D. A., \& Pathmarajah, T. (2015). Mitigation of delays attributable to the contractors in the construction industry of Sri Lanka - consultants' perspective. Engineer, 48(1), 21-30.

Ekanayake, E., \& Perera, B. (2016). Appropriate delay analysis techniques to analyse delays in road construction projects in Sri Lanka. Built Environment Project and Asset Management, 6(5), 521-534.

Ennis, C. (2011). Evaluating disruption costs on major construction projects. Technology and Construction Bar Association's Annual Conference, (pp. 1-26). london.

Gibson, R. (2015). Practical Guide to Disruption and Productivity Loss on Construction and Engineering Projects (3 ed.). United Kingdom: John Wiley \& Sons, Ltd.

Jayalath, C. (2012). Arguing Construction Claims. Colombo: S. Godage \& Brothers (Pvt.) Ltd.

Jayasena , S., \& Alwis, P. (2011). Disruption Claims in Sri Lankan Construction Industry. 15th Pacific Association of Quantity Surveyors Congress, (pp. 94-101). Colombo.

Jelodar, M. B., Yiu, T. W., \& Wilkinson, S. (2016). Dispute Manifestation and Relationship Quality in Practice. Journal of Legal Affairs and Dispute Resolution in Engineering and Construction, 8(1).

Jonathan, D. (2009). Extension of Time Provisions. Lexology. Retrieved from http://www.lexology.com/library/detail.aspx?g=9ff71690-30db-438d-8b23-do5931d370ec

Keane, P. J., \& Caletka, A. F. (2015). Analysis of construction delays (Second Edition ed.). JohnWiley \& Sons, Ltd.

Kikwasi, G. (2013). Causes and effects of delays and disruptions in construction projects in tanzania. Australasian Journal of Construction Economics and Building - Conference Series, 1(2), 52.

Klee, L. (2018). International Construction Contract Law (2 ed.). Hoboken: JohnWiley \& Sons Ltd.

Nagata, M. F., Manginelli, W. A., Lowe, J. S., \& Trauner, T. J. (2018). Construction Delays (3rd ed.). Elsevier.

National Construction Association of Sri Lanka. (2014). National Construction Association of Sri Lanka. Retrieved from http://www.ncaslsouth.com/PAYMENTS.pdf

Nelson, D. (2011). The Analysis and Valuation of Disruption. Journal of Hill International, 31.

Perera , B., \& Sudeha , H. (2013). A Framework to select the most suitable Delay Analysis Technique for Building Construction through a consideration of Utility Factors. The Planning Research Journal, 3(2), 11-29.

Perera, B. A., Wijewickrama, M. K., Goonawardana, P. J., \& Jayalath, C. (2019). Improving the efficacy of delay notification process of construction projects in Sri Lanka. International Journal of Construction Management, 1-14.

Pinamang, P. A., Gyamfi , T. A., Danso, H., \& Kwame, J. A. (2018). Schedule delay analysis of construction projects in ghana: objectives, importance and effects. Civil and Environmental Research, 10(4), 25-30.

Ramachandra, T., Rotimi, J. O., \& Gunaratne, S. (2014). Reasons for contractors' delay claims failures in Sri Lanka. Procs 3oth Annual ARCOM Conference (pp. 475-484). Portsmouth: Association of Researchers in Construction Management.

Shahsavand, P., Marefat, A., \& Parchamijalal, M. (2018). Causes of delays in construction industry and comparative delay analysis techniques with SCL protocol. Engineering, Construction and Architectural Management, 25(4), 497-533.

Tan, C. K. (2012). The feasibility use of the UK delay and disruption protocol in malaysia construction industry. Doctoral dissertation, UTAR.

Tan, Y., Shen, L., \& Yao, H. (2011). Sustainable construction practice and contractors' competitiveness: A preliminary study. Habitat International, 35, 225-230

Taylor, J. M. (2010). Dispute Resolution U.S Commercial Construction : A practical approach. W113-Special Track 18th CIB World Building Congress, (pp. 25-34). 
Trauner, T. J., Manginelli, W. A., Lowe, J. S., Nagata, M. F., \& Furniss, B. J. (2009). Construction Delays (2nd ed.). Elsevier. Retrieved from https://www.sciencedirect.com/science/article/pii/B9781856176774000027

Vatalis, K. I., Manoliadis, O. G., \& Charalampides, G. (2011). Assessment of the economic benefits from sustainable construction in Greece. International Journal of Sustainable Development \& World Ecology, 18(5), 377-383.

Ward, P. (2011). A UK and Australian Perspective of the Suitability of the SCL Protocols' Provisions for Dealing with Float for Adoption and Use by the Australian Construction. In: 27th Annual ARCOM Conference [online], (pp. 5-7). 